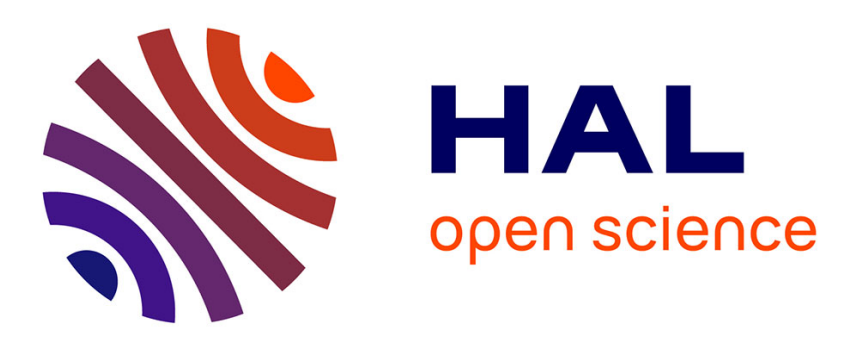

\title{
Behaviour of spreading molten metal drops deposited by fusion
}

\author{
Julien Chapuis, Fabien Soulié, Cyril Bordreuil, Gilles Fras
}

\section{To cite this version:}

Julien Chapuis, Fabien Soulié, Cyril Bordreuil, Gilles Fras. Behaviour of spreading molten metal drops deposited by fusion. Experimental Thermal and Fluid Science, 2013, 48, pp.29-36. 10.1016/j.expthermflusci.2013.02.005 . hal-00825151

\section{HAL Id: hal-00825151 \\ https://hal.science/hal-00825151}

Submitted on 23 May 2013

HAL is a multi-disciplinary open access archive for the deposit and dissemination of scientific research documents, whether they are published or not. The documents may come from teaching and research institutions in France or abroad, or from public or private research centers.
L'archive ouverte pluridisciplinaire HAL, est destinée au dépôt et à la diffusion de documents scientifiques de niveau recherche, publiés ou non, émanant des établissements d'enseignement et de recherche français ou étrangers, des laboratoires publics ou privés. 


\title{
Behavior of a spreading macro-drop of liquid metal during deposit
}

\author{
J. Chapuis, F. Soulié, C. Bordreuil \& G. Fras \\ Laboratoire de Mécanique et Génie Civil (LMGC), Université Montpellier 2, CNRS
}

\begin{abstract}
An experimental approach is presented in order to study the evolution of the spreading of a macro-drop of liquid metal. The objective of this work is to supply qualitative and quantitative information during the deposit of liquid metal in static pulsed Gas Metal Arc Welding (P-GMAW). The experimental results are analyzed in the light of dimensionless numbers in order to identify the involved physical mecanisms and appreciate the heat and mass effects on the behavior of such a macro-drop.
\end{abstract}

Keywords:

\section{Introduction}

The presence of solid-liquid-gas interfaces, and related interfacial phenomena, play an extremely important role in the process called "to high temperature" such as welding [4, 9], both in normal conditions and in the case of extreme stress. In GMAW process particularly, these interfaces take an important place both in the metal transfers in the arc and in the weld pool. The shape of the droplets, in relation with the process parameters, contribue to define the type of welding mode. It is directly linked to the competition between volumic forces, such as gravity or electromagnetic forces, and interfacial phenomena such as surface tension or drag forces. These phenomena, combined with heat and mass transfers, also define the shape of the weld pool and thus the final quality of the welding operation.

The competition between several physical effects are underlined in welding operations in severe conditions like in high speed welding for which humping phenomenon can appear. Humping, by introducing characteristic defects in the weld (in the form of a string of mass of solidified metal, the "humps"), is a limit to the speed of the process, and therefore productivity. The first experimental studies have defined the humping as a series of undulations of the fusion line [? ]. From a physical point of view, one of the mechanisms identified in the onset of humping is the Rayleigh instability which leads to a disruption of the flow of the liquid stream [? ]. Works on this theme allow better understanding of heat transfer, fluid motion [2] and behavior of the weld pool $[6,8,3]$. Many of these works $[8,3,6,2]$ are

Preprint submitted to Experimental Thermal and Fluid Science based mainly on numerical studies, experiments with high speed video to validate some of the results. This phenomenon of humping may appear also with other materials, such as the deposition of wax. Schiaffino and Sonin [12] also offers an interesting study, based on dimensional analysis in the case of a static configuration repository.

The main goal of the present work is to better understand the physical mechanisms involved in the behavior of a weld pool in pulsed GMAW (Gas Metal Arc Welding, P-GMAW), and their relative importance. The study is based on an experimental approach (sections 2 and 3); the results are analysed thanks to dedicated numerical libraries and dimensionless parameters (section 4) and discussed in relation with the welding parameters (section 5).

\section{Deposit of liquid metal droplets on a solid target}

The purpose is to study the shape and the spreading of the macro-drop according to the heat and mass transferts supplied by the deposit of droplets of feed wire with the stationary P-GMAW process. The macro-drop is assumed to be axisymetric with low penetration (the liquid metal forms a drop of liquid at the surface of the solid target). Figure 1 presents the main geometric parameters necessary to describe the evolutions of the shape of the macro-drop and of the contact line (line at the interface solid-liquid-gaz). The geometry of the macro-drop is defined by the height $h$, the radius at its bottom part $R$ defining the base lenght and the contact angles $\theta$ at the 


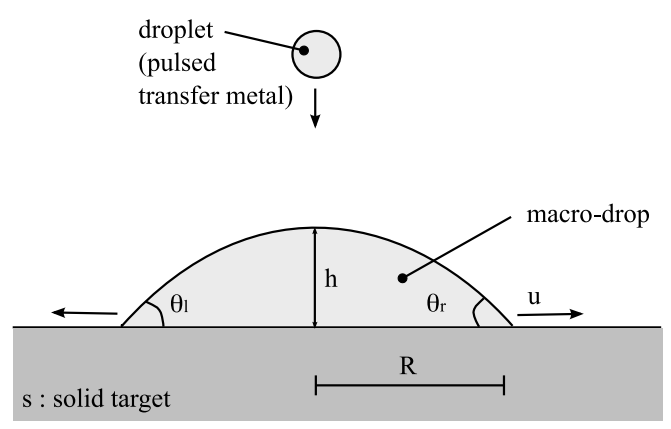

Figure 1: Geometrical description of the deposit and spreading of macro-drop during GMAW static operation.

interface solid-liquid-gaz. These measured parameters are used to determine other parameters describing the behavior of the macro-drop such as its volume $V$ or the speed of spreading $u$ corresponding to the contact line speed.

The physical characteristics required to describe and to analyse the phenomena involved in the behavior of the macro-drop are given in table 1.

\begin{tabular}{lll}
\hline & Characteristics (units) & Values \\
\hline$\gamma$ & surface tension $\left(\mathrm{N} . \mathrm{m}^{-1}\right)$ & 1,67 \\
$\rho$ & density $\left(\mathrm{kg} \cdot \mathrm{m}^{-3}\right)$ & 7200 \\
$\mu$ & viscosity $\left(\mathrm{kg} \cdot \mathrm{m}^{-1} \cdot \mathrm{s}^{-1}\right)$ & 0,06 \\
$c_{p}$ & specific heat $\left(\mathrm{J} \cdot \mathrm{kg}^{-1} .{ }^{\circ} \mathrm{K}^{-1}\right)$ & 753 \\
$T_{f}$ & fusion temperature $\left({ }^{\circ} \mathrm{K}^{-1}\right)$ & 1798 \\
$L$ & enthalpy of melting $\left(\mathrm{J} \cdot \mathrm{kg}^{-1}\right)$ & $2,77.10^{5}$ \\
$\lambda$ & thermal conductivity $\left(\mathrm{W} \cdot \mathrm{m}^{-1} .{ }^{\circ} \mathrm{K}^{-1}\right)$ & 26 \\
\hline
\end{tabular}

Table 1: Numerical values of physical characteristics [8].

\section{Experimental setup and procedures}

\subsection{Experimental setup}

Experiments are realised on a platform specifically dedicated to the study of arc welding processes. This platform allows the synchronized data acquisition of different kinds of signal (process, thermal, mechanic) and video images during arc welding. Arc welding is a really noisy environment because of the perturbation due to electromagnetic noise and radiation from the arc and specific developements were realised for this platform. Stationary spot welds are made using the Pulsed Gas Metal Arc Welding process (Oerlikon CitoWave $500)$ to observe non isothermal spreading of weld pools. The target is a steel disk of $10 \mathrm{~mm}$ in thickness and 150 $\mathrm{mm}$ in diameter. The contact tip to work distance is

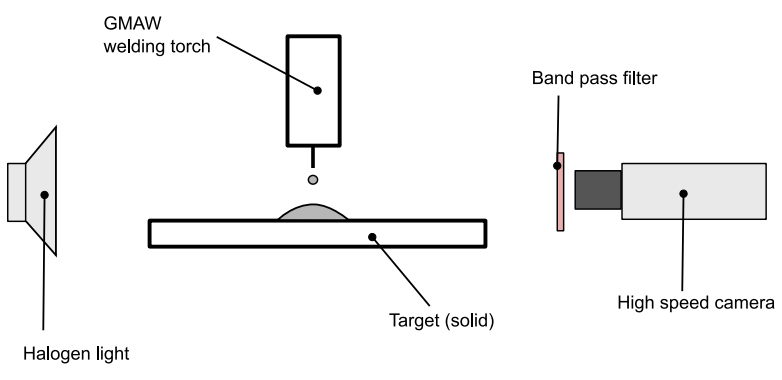

Figure 2: Experimental set-up for back-lit shadow graphic recording.

equal to $20 \mathrm{~mm}$ and ER70S steel welding wire is used for welding experiments (wire diameter: $1 \mathrm{~mm}$ ). Welding current and arc voltage are recorded at $30 \mathrm{kHz}$ sampling rate. The temperature history at several locations (20 and $30 \mathrm{~mm}$ from the center of metal deposit), is measured with thermocouples of $0.6 \mathrm{~mm}$ diameter Type $\mathrm{K}$ wires, glued with epoxy to the plate surface. A highspeed camera (Phantom V5.0) with a back-lit shadow graphic method records weld pool images at a rate of 4000 frames per second so that weld pool radius and apparent liquid-solid contact angle histories can be measured (see fig. 2). A $650 \pm 10 \mathrm{~nm}$ band pass filter is used to attenuate arc light for clear images of weld pool growth and weld metal transfer.

\subsection{Experimental procedures}

The test campaign is based on a reference test (marked R), for which the parameters are the following: welding time: $4 \mathrm{~s}$, wire feed speed: $6 \mathrm{~m} / \mathrm{min}$, frequency of droplets: $113 \mathrm{~Hz}$, initial temperature of solid target: $20^{\circ} \mathrm{C}$ and gaz composition: $8 \% \mathrm{CO}_{2}$ and $92 \%$ Argon. In order to study the behavior of the macrodrop, we vary several parameters as those cited for the reference test. The choice of these different parameters is given in table 2; R corresponds to the values for reference test, $S$ for variation of welding durations, WS for variation of wire feed speed, $\mathrm{F}$ for variation of frequency of droplets deposit, $\mathrm{T}$ for variation of initial temperature of solid target and $\mathrm{G}$ for variation of chemical gaz composition (mixture of Argon and $\mathrm{CO}_{2}$ ).

\section{Data analysis}

\subsection{Numerical libraries}

In complement to the experimental platform of synchronised data acquisition, two numerical open source libraries were developped. They offer the possibilities of easy management of the large flow of multi-physical 


\begin{tabular}{cccccc}
\hline Test code & Welding duration $(\mathrm{s})$ & Wire speed $(\mathrm{m} / \mathrm{min})$ & Frequency $(\mathrm{Hz})$ & Target temp. $\left({ }^{\circ} \mathrm{C}\right)$ & $\mathrm{Gaz} \% \mathrm{CO}_{2}$ \\
\hline R & 4 & 6 & 113 & 20 & 8 \\
S & $4,6,8$ & 6 & 113 & 20 & 8 \\
WS & 4 & $4,6,8,10$ & 113 & 20 & 8 \\
F & 4 & 6 & $40,70,113,200$ & 20 & 8 \\
T & 4 & 6 & 113 & $20,300,600$ & 8 \\
G & 4 & 6 & 113 & 20 & $0,8,18,30$ \\
\hline
\end{tabular}

Table 2: Values of experimental parameters used in tests.

experimental data (up to 2 Go per test) in order to compare and analyze the experimental results. The library $\mathrm{BAME}^{1}$ is used for the analyse of the whole data, whereas the library erCv $\mathrm{Cv}^{2}$ is dedicated to image analysis [11].

Measurements of weld pool dimensions are made using the erCv library (see figure 3). The erCv library is designed to facilitate the measures of the characteristic parameters (geometries and times) of evolution of a weld pool, with huge flows of processed images (up to 30,000 frames per test). Several functions have been developped (using the BAME and erCv libraries) in order to extract the evolution of the height $h$, the base radius $R$ with time on the base of the pictures supplied by the video acquisition. The apparent contact angles $\theta$ are determined with linear regression or least square method on the filtered profile of the macro-drop. This method allows the treatment of more than 1000 frames per test to be done. It is then possible to study the evolution of geometrical parameters with welding time but also computed information such as the welding energy or the volume of the macro-drop.

\subsection{Dimensionless numbers}

An important number of different physical phenomenon are involved in welding operations and a dimensionless analysis can be an interesting way to study their influences [10][5][1]. The Buckingham $\pi$-theorem was used to determine the appropriate dimensionless parameters containing the welding variables and material properties that affect the welding process. If a system can be defined with $n$ variables that can be expressed in terms of $m$ fundamental units, namely for GMAW mass $(M)$, lenght $(L)$, time $(T)$, temperature $(\theta)$ and current intensity $(I)$, the Buckingham $\pi$-theorem allows the system to be defined with the help of $n-m$ dimensionless groups $\pi_{i}$ (the ' $\pi^{\prime}$ label with numerical subscript is tradionally used to represent a dimensionless group of variables in dimensional analysis).

\footnotetext{
${ }^{1}$ https://subver.lmgc.univmontp2.fr/BAME

${ }^{2}$ https://subver.lmgc.univmontp2.fr/erCv
}

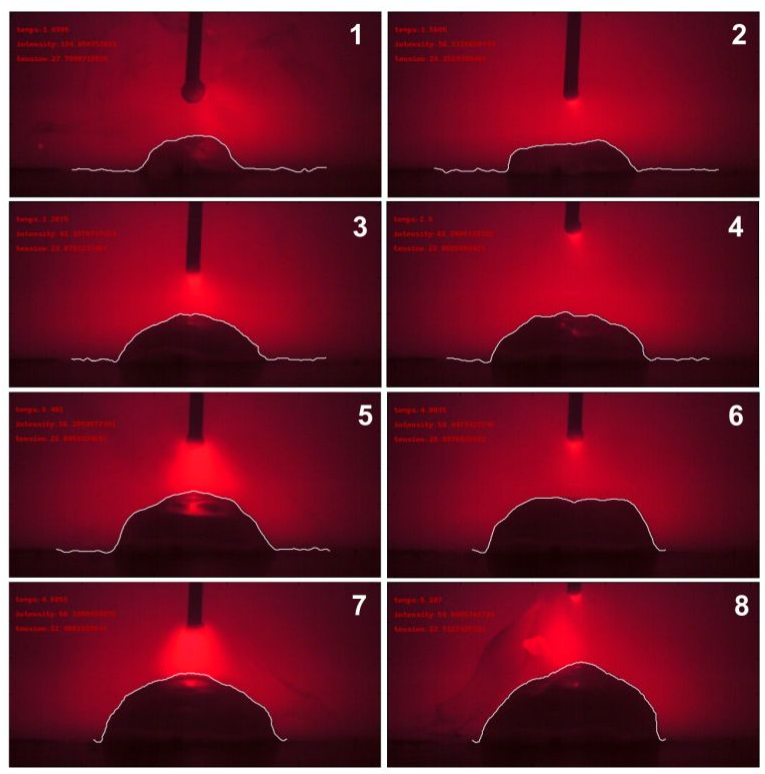

Figure 3: Contour detection with erCv library for several steps of macro-drop spreading. 
The number of variables potentially involved in the description of GMAW operations is very important : voltage, current, wire feed speed, wire feed diameter, stick-out, chemical composition of gas, surface tension, initial temperature of the solid part, thermal conductivity, specific heat, density of metal, electric resistivity, gaz flow rate, contact angles, base radius, height of the macrodrop, speed of the contact line... Some of these variables are linked each other and the number of variables necessary to the description can be reduced. For example, the volume of the macro-drop is directly related to the wire feed speed and wire diameter, to the base radius, height and contact angles of the macrodrop. The welding power can be more relevant than the voltage and current alone by taking also into account the stick-out, the wire feed speed and diameter and the electrical resistivity. The effect of the chemical composition of gas can be described by the surface tension and the observed wetting. The temperature is taken into account as a temperature difference $\Delta T$ between the fusion temperature $T_{f}$ and the intial temperature of the solid target $T_{0}: \Delta T=T_{f}-T_{0}$.

With these considerations, we can consider four fundamental units and nine variables for the description of the behavior of the macro-drop system: the base radius $R$, the height at the center $h$, the speed of spreading $u$, the welding power $P$, the surface tension $\gamma$, the temperature $\Delta T$, the thermal conductivity $\lambda$, the specific heat $c_{p}$ and the density $\rho$. The five dimensionless groups are derived from these variables: $\pi_{1}=\frac{R \rho c_{p}^{1.5} \sqrt{\Delta T}}{\lambda}$, $\pi_{2}=\frac{h \rho c_{p}^{1.5} \sqrt{\Delta T}}{\lambda}, \pi_{3}=\frac{u}{\sqrt{\Delta T c_{p}}}, \pi_{4}=\frac{P \rho c_{p}^{1.5}}{\lambda^{2} \sqrt{\Delta T}}, \pi_{5}=\frac{\gamma \sqrt{c_{p}}}{\lambda \sqrt{\Delta T}}$ The dimensionless groups can be combined to yield meaningful dimensionless numbers such as the capillary number $\mathrm{Ca}$, the Weber number $W e$, the Bond number $B o \ldots$ or parameters describing the global shape of the macro-drop such as its spreading $R / h$. They can also be directly used like the dimensionless group $\pi_{4}$ that describes the energy supplied both by the welding power or preheating operations.

\section{Results and discussion}

According to the involved process in welding operation and to the global shape of the macro-drop (that can be assumed to a spherical cap in a first approach), its evolution seems to be a competition between several physical effects such as gravity, capillarity, inertia, thermics, viscosity...

Some characteristics of evolution can be observed for all the experiments. These main characteristics are presented and discussed for tests in reference configuration (' $\mathrm{R}$ ' tests). The evolution of the shape of the macrodrop can be divided in three main periods. The first one corresponds to the creation of the macro-drop, the second one to a regular spreading and the last one to the solidification. The figure 4 shows the two first periods of evolution of the base of the macro-drop during spot welding. The first step corresponds to transient period: arc initiation and creation of the macro-drop (initiation of the droplets deposit) with a rapid increase of the base radius. We can observe a first very huge increase of the base radius between $0.5 s$ and $0.65 s$ after the beginning of the welding operation. This evolution is a combined effect of the rapid increase of the base of the macrodrop at the beginning of welding and of the numerical method based on treshold elevation to detect the macrodrop on frames. The initial real macrodrop spreading speed in first period is physically given by the evolution between $0.7 s$ and $1.4 s$ (in figure 4); the average speed of displacement of the contact line is $u=4.06 \mathrm{~mm} / \mathrm{s}$. This initial rapid macro-drop spreading is due to kinetic energy of depositing droplets on flat surface and direct arc heating of the solid target. This direct arc heating facilitates the rapid spreading of the macro-drop. After this initial transient step, the spreading of the macro-drop is more gradual, and the heat flow is not directly ensured by the arc heating but by conduction from the melting zone to the solid target. The regular growth of the macro-drop is supplied by the mass transfer due to wire feed. The average spreading speed of the macrodrop is three times lower than in the first step $(u=1.23 \mathrm{~mm} / \mathrm{s})$. At the arc extinction, the weld pool spreading is stopped with arresting of the contact line; the inertial effect can then be supposed negligible in regards of surface tension effects. Moreover, the Weber number $W e$ in the range $10^{-3}$ to $10^{-2}$ for all the experiments shows the importance of surface tension effects on inertial effects in the governing of macro-drop shape and spreading. The capillary number $C a$ lower than $2.10^{-5}$ underlines the minor effect of viscosity in regard of surface tension, whereas the Bond number $B o=2.5$ shows a quite well balanced contribution of gravity and capillary effects on the macro-drop.

The evolution of contact angles during the spot welding are similar for the left and right sides (figure 6). The evolution of contact angle can be influenced by the cleanliness and the roughness of the solid target. Nevertheless, the observed disturbancies and minor asymmetry are mainly due to the oscillations of the weld pool because of the non-symmetric arc and input droplets. We can also observe the two first 


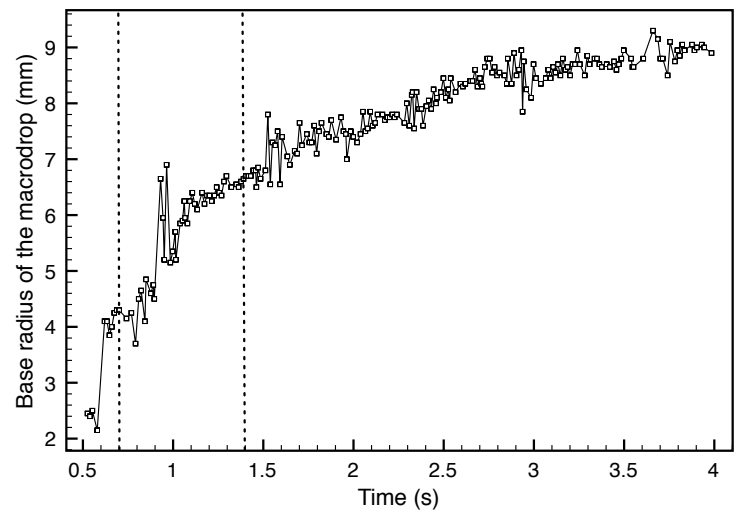

Figure 4: Evolution of the base radius of the macrodrop with time. This evolution is characteristic of the ones obtained for all the tests, only data for ' $\mathrm{R}$ ' test are plotted. The vertical dashed lines are drawn as guide for the eyes, in order to distinguish the two main periods of base spreading.

periods of evolution. The first one, corresponding to the macro-drop creation, is characterised by quite huge variations of contact angles due to arc initiation and droplets impacts on flat surface with small amount of liquid metal. The second one, with lower variation in magnitude, corresponds to the growth of the macrodrop with constantly increasing volume and regular spreading.

The wetting of the macro-drop can also be influenced by the chemical composition of materials involved in the formation of the macro-drop. This phenomenon is clearly shown on figure 5. For equivalent power welding conditions, for a same relative spreading $R / h$, the values of wetting angle decrease with the $\mathrm{CO} 2$ amount increase in gaz mixture. This graph underlines the wetting improvement due to chemical composition.

The increasing wire feed speed has a clear influence on the evolution and shape of the macro-drop as shown on figure 7. The growth of the macro-dop is clearly linked to the mass transfer and kinetic energy due to droplets deposits but not only. When the wire feed speed increases, the global free shape of the macrodrop changes from a spherical cap to a paraboloïd cap. The mass transfer and surface tension effects cannot explain alone this change, it is also due to the increasing energy associated to the wire feed speed increase. The increased welding power supplies more energy to the macro-drop system that facilitates the spreading of the macro-drop. Figure 8 shows the combined effect of mass transfer (variable $V$ ) and power (variable $\pi_{4}$ ) on

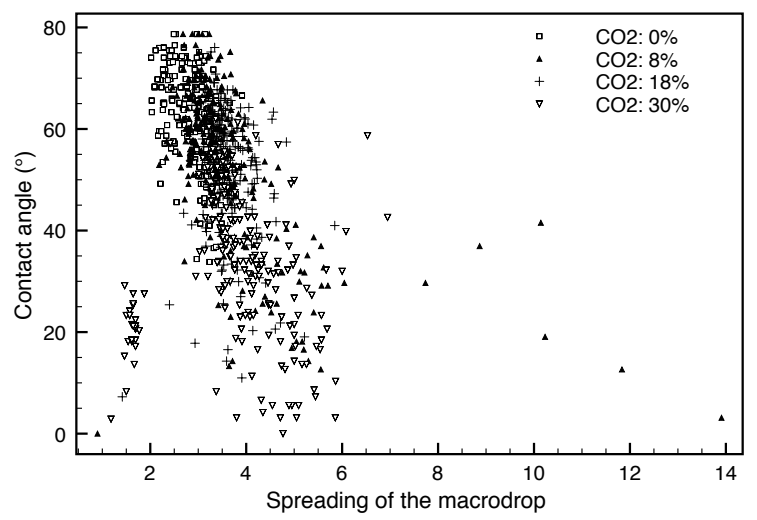

Figure 5: Contact angle in relation with the spreading of the macrodrop $(R / h)$ for several chemical compositions of the welding gaz (mixture Argon and CO2, 'G' tests). This graph describes the wetting for a given global shape of the macro-drop.

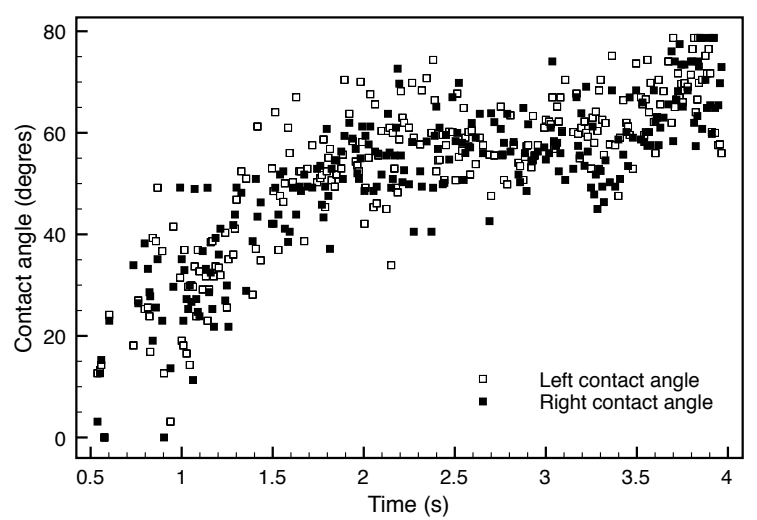

Figure 6: Evolution of the left and right contact angle of the macrodrop with time. Data are plotted for 'R' test. 


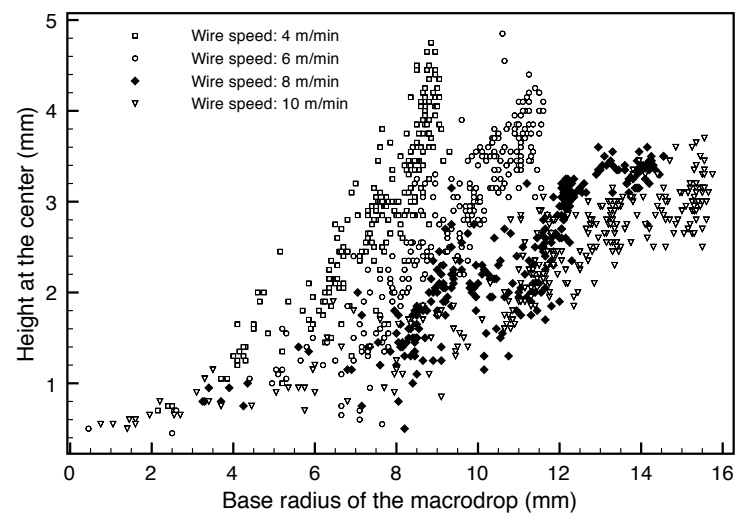

Figure 7: Evolution of the height of the macrodrop in relation with its base radius for several wire speeds ('WS' tests). The measured data give indication on the global shape of the macrodrop and its spredaing.

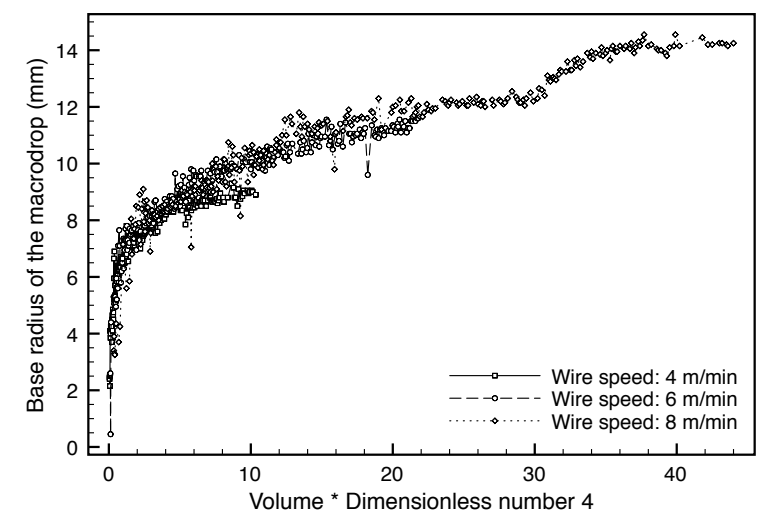

Figure 8: Evolution of the base radius of the macrodrop in relation with mass transfert and energy effects. Dimensionless number 4: $\pi_{4}=$ $\frac{P \rho c_{p}^{1.5}}{\lambda^{2} \sqrt{\Delta T}}$. Data are plotted for 'WS' tests.

the evolution of the macro-drop.

This effect of heat and energy can also be observed on the results of T-type experiments. Figure 9 shows the evolution of the average contact angle with the increasing volume of macro-drop for several initial temperatures of the solid target. We can observe a clear difference in the values of contact angle between no-preheating configuration (initial temperature equals to $293^{\circ} \mathrm{K}$ ) and preheating configurations $\left(593^{\circ} \mathrm{K}\right.$ and $893^{\circ} \mathrm{K}$ ). The preheating facilitates the wetting of the macro-drop. Neverteheless, it seems there is no difference inbetween the two configurations of preheating. The spreading of the macrodrop appears then to be governed by thermal effects: heat transfer, preheating... as shown on figure 10 .

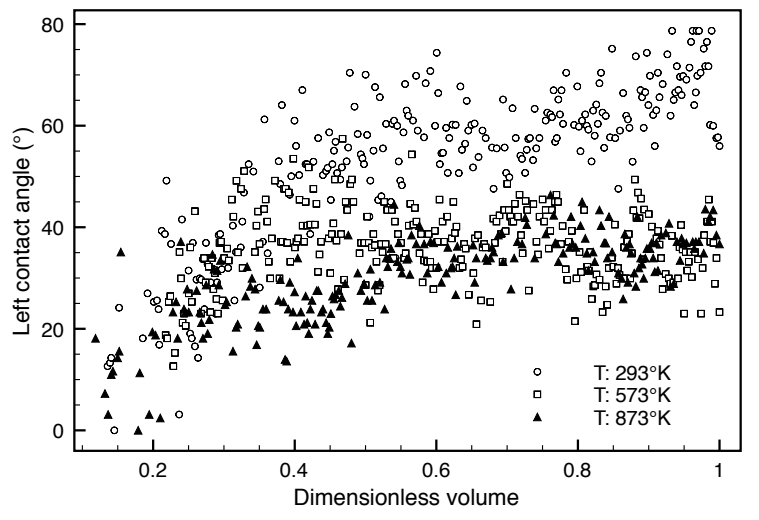

Figure 9: Evolution of the wetting of the macrodrop (contact angle) in relation with the normalized volume of the macrodrop for the different initial values of the temperature of the solid target (' $T$ ' tests).

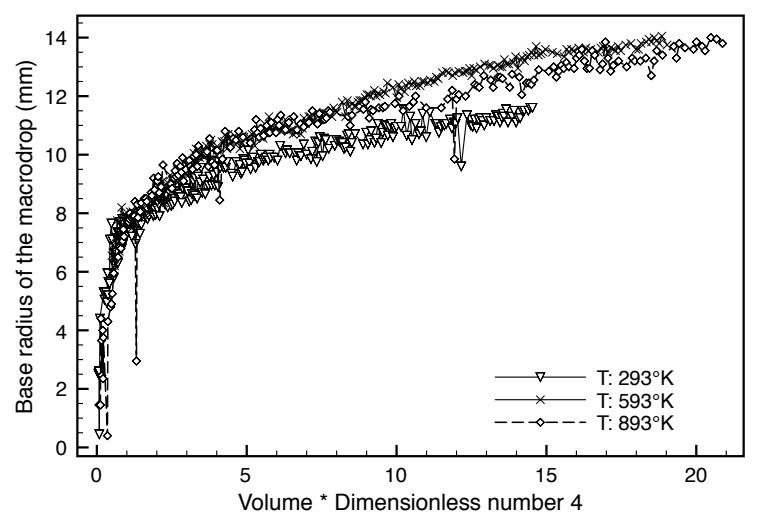

Figure 10: Evolution of the base radius of the macrodrop in relation with mass transfert and energy effects. Dimensionless number 4: $\pi_{4}=$ $\frac{P \rho c_{p}^{1.5}}{\lambda^{2} \sqrt{\Delta T}}$. Data are plotted for ' $\mathrm{T}$ ' tests. 


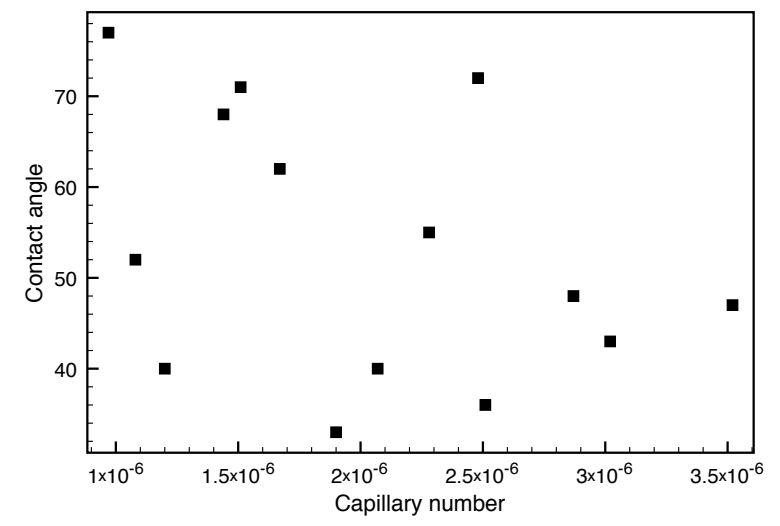

Figure 11: Contact angle vs capillary number $\mathrm{Ca}$. The graph synthesizes the data obtained for the different types of experiments. The values of contact angle and spreading speed required for the calculation of $\mathrm{Ca}$ are the average final values obtained before the welding operation stops.

The several experiments show the importance of capillary and surface tension effects in the behavior of the macrodrop, mainly in the definition of its global shape. Nevertheless, as figure 11 shows, we can not observe direct relationship between contact angle evolution and capillary number $\mathrm{Ca}$ like in Hoffman's law [7]. The spreading of the contact line seems thus not be only and directly linked to capillary effects. Rather, the spreading of the macrodrop appears to be governed by heat and energy transfers. The Peclet number $P e$ approximatively in the range 1 to 6 , in comparison with the small values of $C a$, confirm that heat transfer and phase change could be the factors that govern the spreading of the macrodrop. The calculated values of Stefan number $S t e>1$ show that heat transfer are mainly involved rather than phase change.

This relationship between heat/energy and spreading is clearly underlined by the importance of the dimensionless group $\pi_{4}$ that combines both the effect of preheating and welding power. It is possible to collapse several experimental results on a same graph thanks to the use of this parameter as shown on figure 12 .

\section{Conclusion}

A specific experimental approach was used in static P-GMAW process to measure geometry histories of a macro-drop of liquid metal during its deposit. The experimental results allowed us to study the spreading of this macro-drop in the very noisy environment of arc welding.

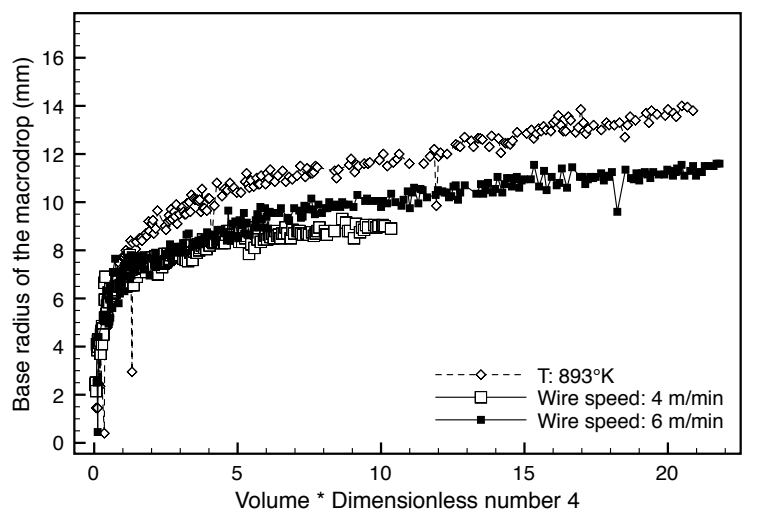

Figure 12: Evolution of the base radius of the macrodrop in relation with mass transfert and energy effects. Dimensionless number 4: $\pi_{4}=$ $\frac{P \rho c_{p}^{1.5}}{\lambda^{2} \sqrt{\Delta T}}$. Comparison for several possibilities in heat transfers (' $\mathrm{T}$ ' and 'WS' tests).

Several physical phenomena are involved in the behavior of this system as shown by the obtained data, but two main phenomena can be identified: surface tension effects and thermal effects.

The qualitative and quantitative nalaysis of experimental data in such a 'basic' configuration show the potentiallity of this approach. Further developments are in progress in order to extend to more complex problems such as undercutting or humping that can happen in high speed welding operations.

\section{Acknowledgement}

This work was partially supported by the ANR project 2007-JC3838, France.

It is a pleasure to thank Denis Cervellin for helpful discussions.

\section{References}

[1] A. Arora, G.G. Roy, and T. DebRoy. Unusual wavy weld pool boundary from dimensional analysis. Scripta Materialia, 60:68-71, 2009.

[2] M. H. Cho and D. F. Farson. Understanding bead hump formation in gas metal arc welding using a numerical simulation. Metallurgical and materials transactions B, 38 B:305-319, april 2007.

[3] M.H. Cho, Y.C. Lim, and D.F. Farson. Simulation of weld pool dynamics in the stationary pulsed gas metal arc welding process and final weld shape. Welding Journal, 85(12):271s-283s, December 2006.

[4] T. DebRoy and S.A. David. Physical processes in fusion welding. Reviews of Modern Physics, 67(1):86-112, January 1995.

[5] M. Van Elsen, F. Al-Bender, and J.-P. Kruth. Application of dimensional analysis to selective laser melting. Rapid Prototyping Journal, 14(1):15-22, 2008. 
[6] H.G. Fan and R. Kovacevic. Droplet formation, detachment, and impingement on the molten pool in gas metal arc welding. Metallurgical and Materials Transactions B, 30B:791-801, August 1999.

[7] R.L. Hoffman. A study of the advancing interface. Journal of Colloid ans Interface Science, 50(2):228-241, February 1975.

[8] Y. C. Lim, D. F. Farson, M. H. Cho, and J. H. Cho. Stationary gmaw-p weld metal deposit spreading. Science and Technology of Welding and Joining, 14(17):626-635, 2009.

[9] K.C. Mills, E.D. Hondros, and Z. Li. Interfacial phenomena in high temperature processes. Journal of Materials Science, 40:2403-2409, 2005.

[10] T.C. Nguyen, D.C. Weckman, and D.A. Johnson. Predicting onset of high speed gas metal arc weld bead defects using dimensional analysis techniques. Science ad Technology of Welding and Joining, 12(7):634-648, 2007.

[11] E. Romero, J. Chapuis, C. Bordreuil, F. Soulié, and G. Fras. Edge detection of weld pool, macrodrop and metal transfer drop in a gtaw and gmaw process, by a new weld image processing library: Ercv. In Proc. of the Int. Conf. on Advances in Welding Science and Technology for Construction, Energy and Transportation, pages 565-569, 2010.

[12] S. Schiaffino and A.A. Sonin. Formation and stability of liquid and molten beads on a solid surface. Journal of Fluid Mechanics, 343:95-110, 1997. 